\title{
アーク溶解法で作製したケイ化ホウ素セラミックスの微細組織と熱電特性
}

\author{
陳立東, 後藤孝, 李 剣輝, 平井 敏雄 \\ 東北大学金属材料研究所, $\mathbf{T} 980-77$ 仙台市青葉区片平2-1-1.
}

\section{Microstructure and Thermoelectric Property of Arc-melted Silicon Borides}

\author{
Lidong Chen, Takashi Goto, Jianhui $\mathrm{Li}$ and Toshio Hirai \\ Institute for Materials Research, Tohoku University, 2-1-1 Katahira Aoba-ku, Sendai 980-77.
}

Received August 29, 1996

\section{SYNOPSIS}

Silicon borides were prepared by arc melting in argon atmosphere using silicon and boron powders in a boron content range from 80 to $94 \mathrm{~mol} \%$. As-melted specimens consisted of $\mathrm{SiB}_{\mathrm{n}}$ and free Si. The contents of free $\mathrm{Si}$ decreased from 30 to $3 \mathrm{vol} \%$ as the boron content in raw material increased from 80 to $94 \mathrm{~mol} \%$. The as-melted specimens were heat-treated in argon atmosphere at temperatures of 1400 to $1700 \mathrm{~K}$. During heat treatment, free $\mathrm{Si}$ reacted with $\mathrm{SiB}_{\mathrm{n}}$ near the $\mathrm{SiB}_{\mathrm{n}}-\mathrm{Si}$ boundary to form $\mathrm{SiB}_{4}$, and as the result $\mathrm{SiB}_{\mathrm{n}}-\mathrm{SiB}_{4}$ composites were obtained. The $\mathrm{SiB}_{\mathrm{n}}-\mathrm{SiB}_{4}$ composites showed larger electrical conductivity and smaller thermal conductivity than the as-melted specimens, which contributes to improvement of thermoelectrical property.

KEY WORDS

Silicon boride, $\mathrm{SiB}_{\mathrm{n}}-\mathrm{SiB}_{4}$ composite, arc melting, heat treatment, electrical conductivity, thermal conductivity, microstructure.

\section{1 緒 言}

シリコンボライド (silicon boride) は、高温にお いて低熱伝導度と高ゼーベック係数を有するとと もに、化学的安定性にも優れることから、高温熱 電材料として有望である ${ }^{1-4)} . \mathrm{Si}$ - B系においては, $\mathrm{SiB}_{4}, \mathrm{SiB}_{6}, \mathrm{SiB}_{\mathrm{n}}(\mathrm{n}=15-49)$ の相が存在するこ とが知られている ${ }^{5-7)}$.中でも， $\mathrm{SiB}_{4}$ 相は低熱伝導 度と高電気伝導度を有するが, ゼーベック係数が 低いため熱電性能は劣っている8)。一方， $\mathrm{SiB}_{6}$ や $\mathrm{SiB}_{\mathrm{n}}$ はゼーベック係数は高いが, 電気伝導度は比 較的小さいため，高い性能指数 $\left(\mathrm{Z}=\alpha^{2} \sigma / \kappa\right)$ を得る には電気伝導度の向上が必要である.

著者らはアーク溶解法を用いてシリコンボライ
ドを合成し，主相の $\mathrm{SiB}_{\mathrm{n}}$ 中に遊離 $\mathrm{Si}$ 相がネットワ 一ク状に入り組んだ $\mathrm{SiB}_{\mathrm{n}}-\mathrm{Si}$ 複合体を得たことを 報告した ${ }^{9)}$. しかし, 遊離Si相は電気伝導度とと もに熱伝導度も增加させたため, 熱電特性の向上 をもたらさない。一方, 主相の $\mathrm{SiB}_{\mathrm{n}}$ 中に高電気伝 導度と低熱伝導度の $\mathrm{SiB}_{4}$ がネットワーク状で分散 する $\mathrm{SiB}_{\mathrm{n}}-\mathrm{SiB}_{4}$ 複合セラミックスが得られれば， 電気伝導度の向上および熱伝導度の低下による熱 電特性の向上が期待される.

$\mathrm{SiB}_{\mathrm{n}}$ や $\mathrm{SiB}_{6}$ を主相とするシリコンボライドは難 焼結のため，その作製法としてはホットプレス ${ }^{2)}$, プラズマ焼結9), 化学気相析出 ${ }^{10)}, ア ー ク$ 溶解法9) などが用いられている。ホットプレスやプラズマ 
焼結法では焼結温度が $1800 \mathrm{~K}$ 以上必要である $2,99$. しかし， $\mathrm{SiB}_{4}$ は高温では熱力学的に不安定で, 1540-1673Kで $\mathrm{SiB}_{6}$ とSiに分解するため5,7,11,12), 焼結法では $\mathrm{SiB}_{\mathrm{n}}-\mathrm{SiB}_{4}$ の複合体を作製することが 困難である。そこで，本研究では，アーク溶解法 で得られた $\mathrm{SiB}_{\mathrm{n}}-\mathrm{Si}$ 複合体を，固相反応を利用し て，高温熱処理することによって， $\mathrm{SiB}_{\mathrm{n}}-\mathrm{SiB}_{4}$ 複 合セラミックスの合成を試みた。ささらに複合化に よる電気伝導度と熱伝導度への影響についても調

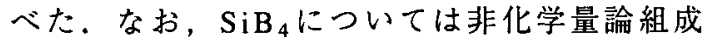
$\left(\mathrm{SiB}_{2.8 \sim 4}\right)$ を有すると報告されており ${ }^{13)}$, その化 学式の表現は決まっていないが，本稿中では $\mathrm{SiB}_{4}$ と記す。

\section{2 実験方法}

原料粉末としてケイ素（Si）粉末とホウ素（B） 粉末を用いた。ホウ素含有量が $80-94 \mathrm{~mol} \%$ の範 囲でそれらの粉末を適量秤量し，少量のエタノー ルとーともにメノウ乳鉢中で混合した後, ペレット 状に圧粉成形した. 得られたペレットをアルゴン 雲囲気中でアーク溶解し，ボタン状試料を作製し た．得られたボタン状試料をさらに1400-1700K の温度範囲でアルゴン雰囲気中において熱処理を 行った。

得られた試料の相組成と結晶構造をX線回折法 により調べた。微細組織は鏡面研磨後にSEM およ びEPMAを用いて観察した。また，ボタン状試料 加短册状試料（約 $10 \mathrm{~mm} \times 4 \mathrm{~mm} \times 2 \mathrm{~mm}$ ) を切り 出し, 直流四端子法を用いて電気伝導率 $(\sigma)$ を 測定した。熱伝導率（ $\kappa$ ）は円板状試料（約 $10 \mathrm{~mm} \phi \times 2 \mathrm{~mm})$ を用い,レーザーフラッシュ法 により測定した。測定は室温から $1200 \mathrm{~K} の$ 温度範 囲で行った。

\section{3 結果と考察}

Fig.1 にアーク溶解したB=90mol\%の試料のX線 回折図形を示す。 $\mathrm{X}$ 線回折の結果, $\mathrm{B}=80-$ $94 \mathrm{~mol} \%$ の範囲で得られた試料は $\mathrm{SiB}_{\mathrm{n}}$ と遊離 $\mathrm{Si}$ の二 相からなっている。Fig.2 には遊離 $\mathrm{Si}$ 相の含有量の 変化を示す．遊離 $\mathrm{Si}$ 相の含有量は原料中のホウ素 含有量の増加とともに減少し，ホウ素含有量が 80 から 94mol\%に增加するにつれて，約30vol\%から 3vol\%に減少した。なお，X線回折により求められ た遊離 $\mathrm{Si}$ の格子定数（a）は文献値 $\left.(0.5431 \mathrm{~nm}){ }^{14}\right)$

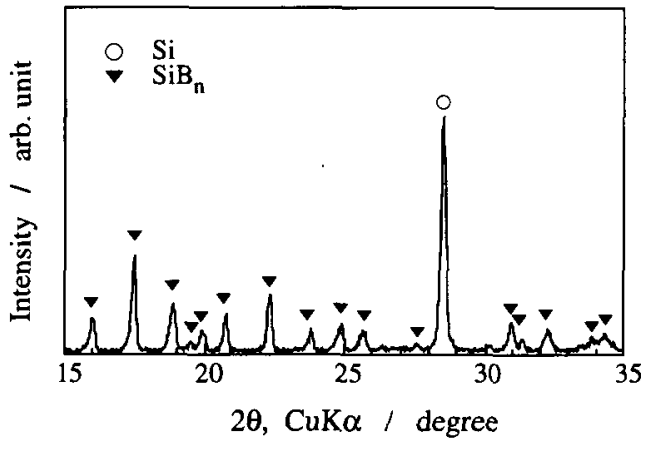

Fig.1 X-ray diffraction pattern of an arc-melted silicon boride. $(\mathrm{B}=90 \mathrm{~mol} \%)$

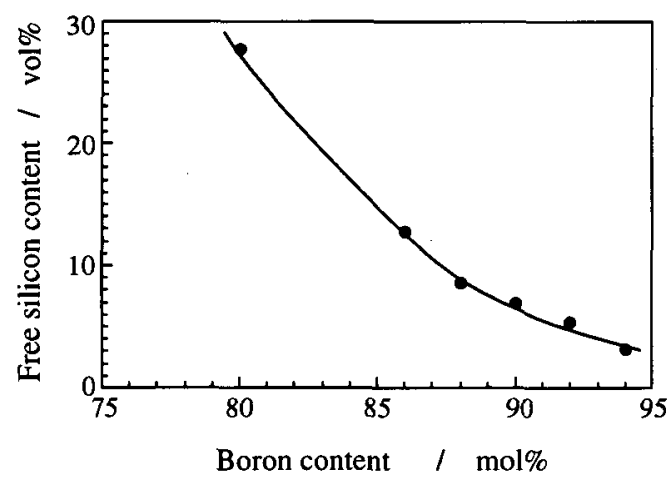

Fig.2 Relationship between free silicon content in arcmelted silicon borides and boron content in raw materials.

より小さく, $0.5415 \mathrm{~nm}$ であった. $\mathrm{Si}$ 中の B の固溶 限度は約 $3 \mathrm{~mol} \%$ で， $\mathrm{B}$ 固溶量が0から $3.0 \mathrm{~mol} \%$ 人增 加した場合，Siの格子定数が $0.5431 \mathrm{~nm}$ から $0.5412 \mathrm{~nm}$ 一と小さくなることが報告されている 5,15,16). 従って, 本実験でアーク溶解した $\mathrm{SiB}_{\mathrm{n}}-\mathrm{Si}$ 中のSiには固溶限度に近い量（約 $3 \mathrm{~mol} \%$ ）のBが 固溶していることが推測される。

$\mathrm{SiB}_{\mathrm{n}}$ - $\mathrm{Si}$ 複合体の微細組織は既に報告したとお りに, B=80-90mol\%では，Si相がネットワーク 状で連続的につながっており， $\mathrm{SiB}_{\mathrm{n}}$ 相はネットワ 一ク状のSi中に存在しているが，B>90 $\mathrm{mol} \%$ では， $\mathrm{Si}$ 相が不連続的に分散するようになる9)。また， ゼーベック係数の相組成による影響はほとんどみ られず，温度が室温から $1100 \mathrm{~K} に 上$ 昇するにつれ て全ての試料のゼーベック係数が約 100 から $300 \mu \mathrm{VK}^{-1}$ に変化することを既に報告した9).

Fig.3にアーク溶解したB=90mol\% の試料をアル 


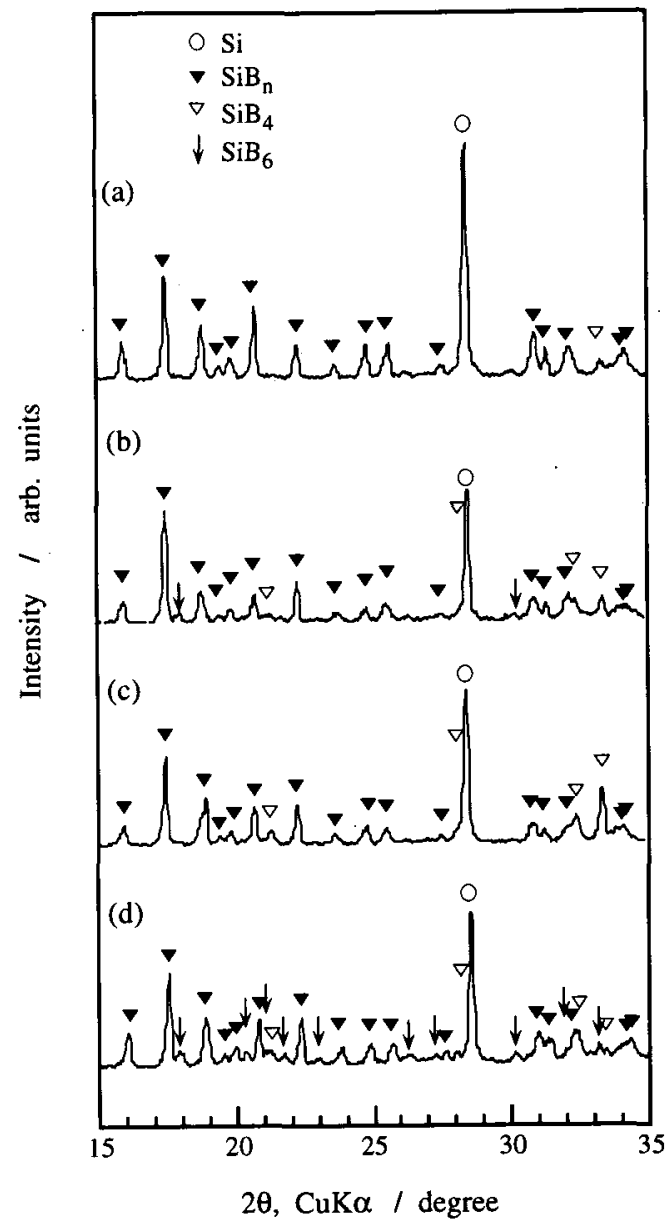

Fig.3 X-ray diffraction patterns of arc-melted silicon boride after heat-treatment. The conditions of heat-treatment are: (a) $1538 \mathrm{~K}, 5 \mathrm{hr}$; (b) $1538 \mathrm{~K}, 40 \mathrm{hr}$; (c) $1673 \mathrm{~K}, 0.5 \mathrm{hr}$; (d) 1673K, 2hr. (B=90mol\%)

ゴン雾囲気中で熱処理した後のX線回折図形を示 す。約 $1538 \mathrm{~K} て 5$ 時間熱処理した試料には，微量 な $\mathrm{SiB}_{4}$ の生成が認められた（Fig.3(a)）。同じ温度 で40時間処理すると, $\mathrm{SiB}_{4}$ 量の顕著な増加は認め られないが, $\mathrm{SiB}_{6}$ の生成が認められた（Fig.3(b)). また, $1673 \mathrm{~K} て ゙ 0.5$ 時間処理すると, $\mathrm{SiB}_{6}$ は認めら れず，新たな生成相は $\mathrm{SiB}_{4}$ のみであった。 $\mathrm{SiB}_{4}$ の 回折強度はより高くなった (Fig.3(c)).一方, 同 温度で 2 時間処理すると, $\mathrm{SiB}_{4}$ 回折線強度が逆に 弱くなり， $\mathrm{SiB}_{6}$ の回折線が出現した。 1500$1673 \mathrm{~K}$ の温度範曲では，短時間の熱処理では $\mathrm{SiB}_{4}$ が生成するが，長時間の処理を行うと，次第に $\mathrm{SiB}_{6}$ の回折線強度が強くなり, $\mathrm{SiB}_{4}$ の回折線強度
が弱くなった。 $\mathrm{SiB}_{6}$ は熱処理温度が高いほど短い 時間で出現する。また，1473K以下では，40時間 熱処理しても新しい回折線の出現は認められなか った。約 $1680 \mathrm{~K}$ 以上では, 短時間の熱処理（10分 以下）でも $\mathrm{SiB}_{6}$ が生成された。

$\mathrm{SiB}_{4}$ は, B粉末と過剩の $\mathrm{Si}$ 粉末を溶解し急冷し て， $\mathrm{SiB}_{6}$ およびSi との混合物として得られること が報告されている7.17)。 また，SiとBの混合粉末て $1473-1673 \mathrm{~K}$ の高温固相反応でも $\mathrm{SiB}_{4}$ が得られる が，一般的には $\mathrm{SiB}_{6}$ と遊離 $\mathrm{Si}$ が共存する7,11,12). 純 粋な $\mathrm{SiB}_{4}$ は化学量論の組成を持つ $\mathrm{Si}$ と B 混合粉末 を $1473 \mathrm{~K} て ゙ 3$ 週間の固相反応によって得られた報 告がある ${ }^{11)}$. $\mathrm{Si}$ 過剩の条件下で $1573 \mathrm{~K}$ 以上の固相 反応で, 遊離 $\mathrm{Si}$ と $\mathrm{SiB}_{4}$ の混合物が生成するが, 長 時間に保持すると $\mathrm{SiB}_{4}$ が熱力学的に不安定なため $\mathrm{SiB}_{6}$ と $\mathrm{Si}$ 一分解することが指摘されている5,7,11,12). $\mathrm{SiB}_{4}$ の分解温度については様々な報告があるが， 一般的には約 $1540 \mathrm{~K}-1673 \mathrm{~K}$ とされている5,7,11,12). 本実験の結果も従来の報告とほほ一致する。本実 験のアーク溶解した $\mathrm{SiB}_{\mathrm{n}}-\mathrm{Si}$ 複合体を高温熱処理 することによって $\mathrm{SiB}_{\mathrm{n}}-\mathrm{SiB}_{4}$ 複合セラミックスを 合成するには，比較的低い温度（1473K以下）で 長時間（数週間以上）で処理するか，または中温 域 $(1573-1673 K)$ で短時間処理するかのいずれ の方法がある。なお，後者では全ての遊離Siを反 応させることは困難と考えられる。

Fig.4に, B=90mol\%の試料の SEM 組織写真 (Fig.4(a)) および1673K，0.5時間で熱処理した後 のSEM組織写真（Fig.4(b)）を示す.Fig.4(a)の黒 い部分 $\mathrm{A}$ と白い部分 $\mathrm{B}$ はそれぞれ $\mathrm{SiB}_{\mathrm{n}}$ と遊離 $\mathrm{Si}$ ある，遊離 Si はネットワーク状の組織になってい る. Fig.4(b)には黒い部分A と白い部分Bの間に灰 色の部分Cが存在する. EPMAによる成分分析に より A， C， Bの順にSi含有量が増加することが分 かった. Fig.3に示したX線回折結果により, 生成 相はSiと $\mathrm{SiB}_{4}$ と $\mathrm{SiB}_{\mathrm{n}}$ との三相であることから，A， C，B部分はそれぞれ $\mathrm{SiB}_{\mathrm{n}}, \mathrm{SiB}_{4}, \mathrm{Si}$ 相であること が推定される。熱処理することにより遊離 Si相と $\mathrm{SiB}_{\mathrm{n}}$ 相の粒界付近において $\mathrm{Si}$ と $\mathrm{SiB}_{\mathrm{n}}$ が反応して $\mathrm{SiB}_{4}$ が生成した。ネットワークの接点部に未反応 のSiが残留しているものの, 全体のSiのネットワ ークがなくなり, $\mathrm{SiB}_{4}$ のネットワークになった。

Fig.5 に熱処理前後の試料の電気伝導率の温度変 化を示す.アーク溶解した試料の電気伝導率は含 

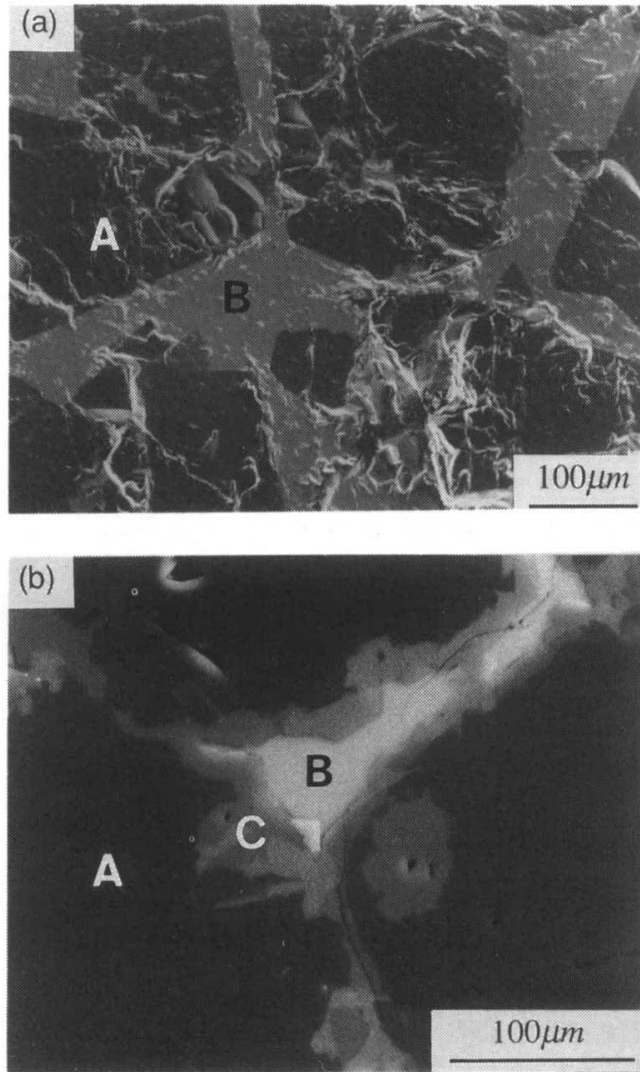

Fig. 4 Microstructures of arc-melted silicon boride.

(a) as-melted; (b) after heat-treatment at $1673 \mathrm{~K}$ for $0.5 \mathrm{hr}$. The $A, B$ and $C$ parts are $\mathrm{SiB}_{n}$, free-Si and $\mathrm{SiB}_{4}$, respectively. $(B=90 \mathrm{~mol} \%)$

有する遊離 $\mathrm{Si}$ 量が大きいほど大きかった。 $1673 \mathrm{~K}$ で熱処理した後, いずれの試料においても電気伝 導率が $30-60 \%$ 上昇した。特に $\mathrm{SiB}_{4}$ をより多く含 む $88 \mathrm{~mol} \% \mathrm{~B}$ の試料は化学気相析出法で合成された 単相の $\mathrm{SiB}_{4}{ }^{8)}$ に近い值を示し, 温度变化もほほ等 しい。これはより $\mathrm{SiB}_{4}$ ネットワークが電気伝導を 支配しているためと考えられる.

Fig.6 に熱処理前後の試料の熱伝導率の温度変化 を示す。アーク溶解した試料の熱伝導率は遊離 $\mathrm{Si}$ 量が大きいほど大きかった。1663Kで熱処理した 後, いずれの試料においても熱伝導率が $20-30 \%$ 低下し，室温から $1100 \mathrm{~K} に$ かけて約 $8 \mathrm{WK}^{-1} \mathrm{~m}^{-1}$ から $6 \mathrm{~W} \mathrm{~K}^{-1} \mathrm{~m}^{-1}$ へ変化し, 従来報告された $\mathrm{SiB}_{4}{ }^{8,12)}$ と $\mathrm{SiB}_{\mathrm{n}}{ }^{4,9)}$ の值とほほ一致する. $\mathrm{SiB}_{4}-\mathrm{SiB}_{\mathrm{n}}$ 複合化に よって電気伝導率が増加するとともに熱伝導率が 低下した。これらの変化は熱電性能指数の向上に 寄与することが期待される.

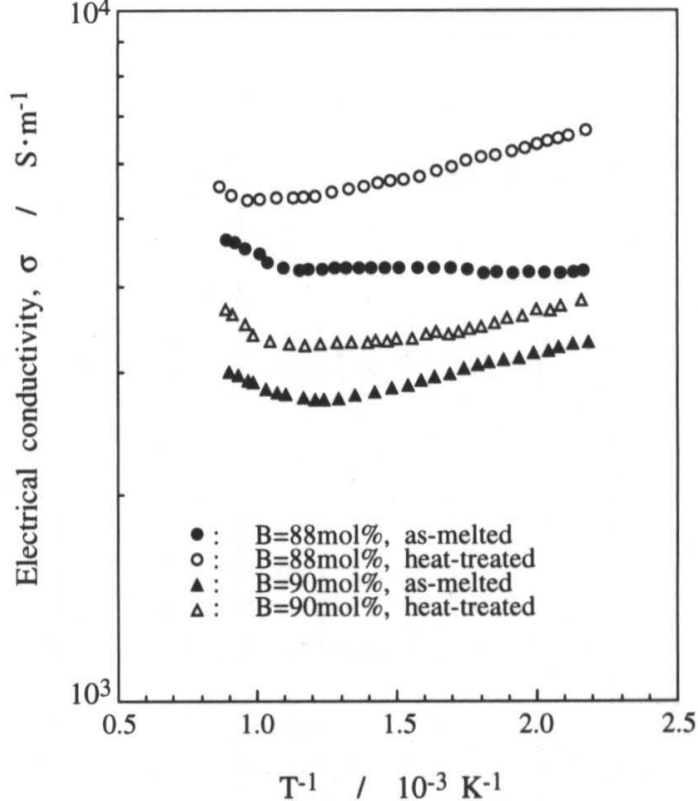

Fig.5 Temperature dependence of electrical conductivity of arc-melted silicon borides before and after heattreatment at $1673 \mathrm{~K}$ for $0.5 \mathrm{hr}$.

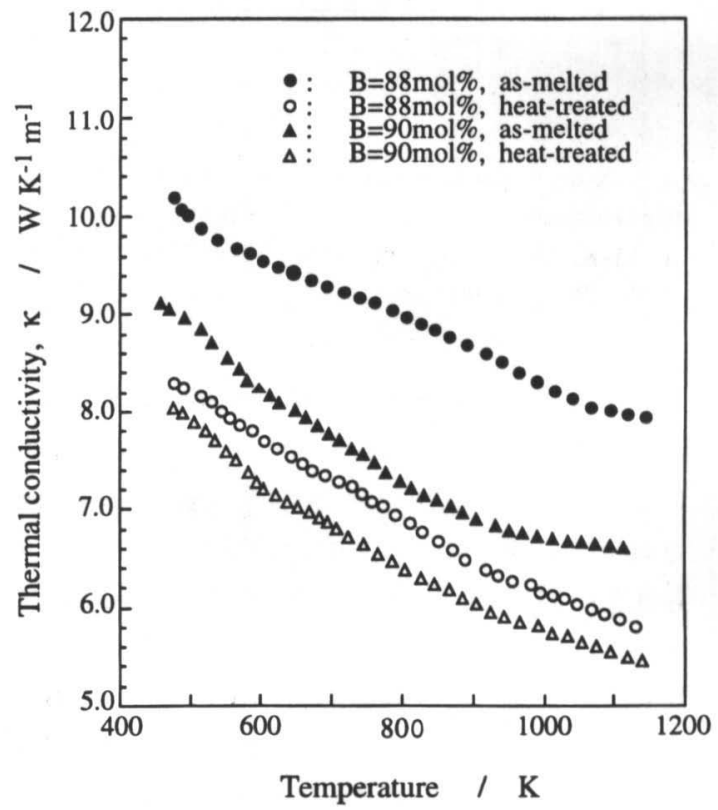

Fig.6 Temperature dependence of thermal conductivity of arc-melted silicon borides before and after heat-treatment at $1673 \mathrm{~K}$ for $0.5 \mathrm{hr}$. 


\section{4 結 言}

アーク溶解したシリコンボライドは $\mathrm{SiB}_{\mathrm{n}}$ と遊離 Si相から成る。アルゴン雲囲気中において $1500-$ $1673 \mathrm{~K}$ で熱処理すると，遊離 $\mathrm{Si}$ 相と $\mathrm{SiB}_{\mathrm{n}}$ 相が境界 付近で反応して $\mathrm{SiB}_{4}$ が生成し, $\mathrm{SiB}_{4}-\mathrm{SiB}_{\mathrm{n}}$ 複合セ ラミックスが得られた。 $\mathrm{SiB}_{4}$ と $\mathrm{SiB}_{\mathbf{n}}$ の複合化によ って, 電気伝導率が増加し熱伝導率が低下した。 これらの变化は熱電性能指数の向上に寄与する.

\section{謝 辞}

本研究の一部は, 科学技術庁振興調整費「傾斜 構造形成によるエネルギー変換材料の開発に関す る研究」, 文部省科学研究費補助金創成的基礎研究 PN0701 挔よび一般研究(B)06453081の援助により 行われた. EPMA分析およびSEM観察は東北大学 金属材料研究所新素材開発施設村上義弘氏にご協 力頂いた。

\section{文 献}

1) C. Wood: Materials Research Society Symposia Proceedings, Vol 97, Ed. by D. Emin, T. L. Aselage and C. Wood (Materials Research Society, Pittsburgh, 1987), p.335.

2) C. Wood, D. Emin, R. S. Frigelson and I. D. R. Mackinnon: ibid., p.33.

3) B. Armas and C. Combescure: J. Less-Common
Met., 47 (1976) 135.

4) J. M. Darolles, T. Lepetre and J. M. Dusseau: Phys. Stat. Sol. (a), 58 (1980) K71.

5) R. W. Olesinski and G. J. Abbaschian: Bull. Alloy Phase Diagrams, 5 (1984) 478.

6) B. Armas, G. Male and D. Salanoubat: J. LessCommon Met., 82 (1981) 245.

7) H. F. Rizzo, B. C. Weber and M. A. Schwarz: J. Amer. Ceram. Soc., 43 (1960) 497.

8) M. Mukaida, T. Goto and T. Hirai: Mater. \& Manufacturing Processes, 7 (1992) 625.

9) 陳, 後藤, 李, 新野, 平井: 電気学会論文誌 $A$, 116-A (1996) 248.

10) M. Mukaida, T. Goto and T. Hirai: J. Mater. Sci. 27 (1992) 255.

11) C. Brosset, B. Magnusson: Nature, 187 (1960) 54.

12) R. S. Feigelson and W. D. Kingery: Ceram. Bull., 42 (1963) 688.

13) M. Bouchacourt and F. Thevenot: Mater. Res. Bull., 17 (1982) 1353.

14) JCPDS Card, File No. 27-1402 (1977).

15) G. V. Samsonov and V. M. Sleptsov: Russ. J. Inorg. Chem., 8 (1963) 1047.

16) J. Hesse: Z. Metallkd., 59 (1968) 499.

17) H. Moissan and A. Stock: Compt. Rend., 131 (1900) 139. 